\title{
The merits of teaching mathematics with variation
}

\author{
Author: \\ Michael Mhlolo ${ }^{1}$ \\ Affiliation: \\ ${ }^{1}$ Faculty of Humanities, \\ Central University of \\ Technology, South Africa \\ Correspondence to: \\ Michael Mhlolo \\ Email: \\ mmhlolo@cut.ac.za \\ Postal address: \\ Private Bag X20539, \\ Bloemfontein 9300, \\ South Africa \\ Dates: \\ Received: 13 June 2013 \\ Accepted: 04 Nov. 2013 \\ Published: 29 Nov. 2013 \\ How to cite this article: \\ Mhlolo, M. (2013). \\ The merits of teaching \\ mathematics with variation. \\ Pythagoras, 34(2), Art. \\ \#233, 8 pages. http://dx.doi. \\ org/10.4102/pythagoras. \\ v34i2.233

\section{Copyright:} \\ (C) 2013. The Authors. \\ Licensee: AOSIS \\ OpenJournals. This work \\ is licensed under the \\ Creative Commons \\ Attribution License.
}

Read online:
There is a general perception that the South African curriculum statements for mathematics create polarity between the 'old' and the 'new', which does not benefit both the teachers and the learners. The new curricula demand a radical shift from the traditional teacher-led approaches that teachers are familiar with, yet does not provide a model of what it might mean to teach for conceptual understanding. This article aims to provide such a model by examining the potential of teaching with variation, which is viewed as an important mathematics teaching and learning style. Proponents of the theory of variation claim that how teachers make available the object of learning to their students has been neglected yet it has a critical influence on learners' learning. This is important for educators as they struggle to make sense of the seemingly contradictory requirements of the new curriculum. In this article a discernment unit comprising four variation patterns is used as a tool to analyse a seemingly rich teacher-led approach to teaching that was observed in one South African Grade 11 mathematics classroom. The results of the analysis and implications for theory and practice are then discussed.

\section{Introduction}

Teaching approaches associated with the 'old' curriculum are characterised as content driven, teacher centred, examination focused and transmission based (Brodie \& Pournara, 2005) and are generally discouraged as they are considered to be inhibitive to learners' deep understanding of mathematics. In contrast, the 'new' is characterised as learner centred and arguments in its favour claim that learners can benefit immensely from its judicious application. Yet these promises have been questioned by critics who doubt that such approaches are appropriate in all cultural and resource contexts. South Africa bears testimony to this doubt as numerous reports have shown how teachers struggle to implement such approaches (Adler, 2009; Brodie \& Pournara, 2005; Long, 2005; Vithal \& Volmink, 2005) and how learners subsequently end up without the envisaged knowledge and skills (Schollar, 2004).

One reason cited for the 'lack of fit' between the espoused and implemented curriculum was that there has been too much emphasis on the philosophical level where the different 'isms' of different schools of thought are full of conflicts which are difficult to resolve in order to arrive at a consensus (Ling, 2012). In South Africa, Vithal and Volmink (2005) made similar observations as they posited that such (new) reforms are driven largely by conjecture, stereotype, intuition, assertion and a host of untested assumptions, rather than by research.

\section{Mayer (2009) contends that}

[o]ur field would be better served by trying to figure out research-based answers to how learning and instruction work rather than by engaging in high-level philosophical arguments about which 'ism' is the best. (p. 197)

Given that the 'new' is not often seen, even in well-resourced Western countries in which school reform movements have been promoting these ideas for many years, Brodie and Pournara (2005) suggest that the next important steps, particularly for research and teacher education, are to critique, adapt, modify and complete these visions in ways that enable teachers and learners to achieve new ways of working in their classrooms. This article aims at contributing to these renewed efforts towards understanding what it might mean to teach mathematics in the traditional way whilst creating opportunities for learners to develop deep understanding of the subject. The article examines the potential of variation theory as an alternative lens through which teaching in the 'traditional' way could possibly be modified and adapted into classrooms that aim to teach for conceptual understanding.

\section{Background to the problem}

In a previous article (Mhlolo, Venkat \& Schäfer, 2012) we analysed 20 lesson transcripts to examine the quality of four teachers' instructional representations of mathematical ideas and 
the potential therein to create opportunities for learners to make connections amongst relatable mathematical ideas. This was premised on the view that making connections in mathematics was critical for a deep understanding of the subject. Lesson transcripts were coded using a three-point scale: faulty connections (level 0), weak connections (level 1) and the strongest connections (level 2). The results showed how one teacher's representations fell into level 2 in $61 \%$ of the cases and into level 0 in only $0.5 \%$ of the cases as compared to the other three, whose representations fell mostly into lower levels. This suggested that this teacher might have created more opportunities for learners to develop higher quality mathematical connections than did the other teachers. This was despite the researchers' observation that the teacher's lessons were generally content driven, teacher centred and transmission based, approaches that are not consistent with the 'new' curricula. Logically, these two opposite observations cannot be seen to be simultaneously valid; hence, this paradoxical observation triggered this interest to search for an alternative lens through which such 'traditional' teaching approaches could be viewed positively. This article is premised on the view that the use of variation in teaching mathematics might provide such a lens. The next question one might then ask is: What does the theory of variation say?

\section{The theory of variation and its application to mathematics teaching}

Variation is about what changes, what stays constant and the underlying rule that is discerned by learners in the process (Leung, 2012). The use of variation in learning and awareness was initially proposed by Marton and Booth (1997). The theory of variation was subsequently developed by Marton and Tsui (2004) as a generic learning theory; over the years researchers have refined and applied it over a broad spectrum of learning areas. With specific reference to mathematics education,

[a] variation interaction is a strategic use of variation to interact with mathematics learning environment in order to bring about discernment of mathematical structure. (Leung, 2012, p. 435)

So a mathematics pedagogy that is rooted in variation is one that purposefully provides learners with the means to experience variation through strategically designed activities in order to create a mathematically rich learning environment (Leung, 2010) that allows learners to discern the object of learning. The 'object of learning' is a special term in variation theory and does not mean the same as 'learning objectives', which point to the end of the process of learning. Instead the object of learning points to the beginning of the process of learning and generally refers to the focus of a teaching situation, the thing to which learning is directed, that is, 'what is to be learnt' (Ling, 2012). It is defined by its critical features that must be discerned in order to constitute the meaning aimed for (Marton \& Tsui, 2004). So as a pedagogic approach, a pattern of variation is a useful tool for structuring teaching to make the learning of the object of learning possible. Marton (2009) proposed four kinds of awareness brought about by different patterns of variation; these are discussed in more detail below.

\section{Contrast (C)}

Marton (2009) describes the awareness brought about by experiencing the difference (variation) between two values as contrast. An observation made by Ling (2012) was that teachers had a tendency to place much emphasis on the use of examples to show similarities. However, according to variation theory, relying solely on similarities is not sufficient. Contrast therefore pre-supposes that to know what something is you have to know what it is not, that is, to discern or learn whether something satisfies a certain condition or not (Leung, 2012). For example, when teaching learners what a triangle is, the teacher should also show learners what a triangle is not by comparing it with other polygons (e.g. quadrilaterals, pentagons, hexagons and circles).

\section{Separation (S)}

Let us take the same example of polygons and assume that the triangle that is initially encountered when the teacher contrasts it with other polygons (non-examples) is a scalene triangle. Because the learner has only encountered a scalene triangle they cannot yet distinguish this particular triangle (scalene) from other triangles. Separation is premised on the view that everything has a multitude of features, each of which gives rise to a different understanding of that thing. Similarly, a scalene triangle has a multitude of features some of which (e.g. shape) just help us to understand it as different from other polygons. If we want others to see a scalene triangle not just as a triangle but in a particular way that distinguishes it from other triangles, then we must focus on certain features that are critical to a certain way of seeing it, known as its 'critical features' (Ling, 2012). In this sense learning is seen as a function of how learners' attention is selectively drawn to the critical aspects of the object of learning. The view is that deliberate attempts to systematically vary certain aspects and keep certain aspects constant may help people to discern 'new' aspects of an object and construct 'new' meanings that might not have been apparent before. Hence, according to Leung (2012), separation is an awareness awakened by a systematic 'refined contrast' obtained by purposely varying or not varying certain aspects in an attempt to differentiate the invariant parts from the whole (p. 435). So when the learner suddenly becomes aware of the scalene triangle through a systematically and deliberately focused variation pattern, we say the scalene triangle is separated from other triangles, and it now has a separate identity. If we do not vary the kind of triangles, we have not helped learners to separate scalene triangles from triangles in general.

\section{Generalisation (G)}

Both Leung (2012) and Chik and Marton (2012) posit that generalisation is a verification and conjecture-making activity checking the general validity of a separated out pattern, which is often a goal of mathematics exploration. Ling (2012) points to links between separation and generalisation in that a pattern of variation can lead to either a separation or generalisation depending on the focus of variation or object of learning. According to Ling, in deciding whether the 
pattern of variation leads to separation or generalisation, we must make clear what the object of learning is. In general, when the focus is on what is subordinate, it is separation: it separates the specific or particular from the general. When the focus is on what is superordinate, the awareness is of generalisation: it can be said about or is applicable to all.

\section{Fusion (F)}

Fusion takes place when the learner's attention is focused on several aspects of an object, a concept or a phenomenon that vary at the same time. The view from a variation theory perspective is that if the learners can only discern individual critical features but fail to achieve the stage of fusion (the simultaneous discernment of all of the critical features and the relationships amongst them), then they may not be able to understand the object of learning thoroughly, and will not be able to apply such knowledge to solve new problems (Ling, 2012). Fusion therefore integrates critical features or dimensions of variation into a whole under simultaneous co-variation. It is important to note that besides synchronic simultaneity when learners focus on different aspects of an object of learning at the same time, diachronic simultaneity also plays a critical role in fusion by connecting variation experiences gained in previous and present interactions (Leung, 2012). This follows the view that learners always bring what they have met before (previous knowledge) to bear on what they are learning now; hence, simultaneous covariation can be explained in terms of both synchronic and diachronic simultaneity.

\section{Discernment unit as the analytical framework}

Leung (2012) proposed an idea of a discernment unit that stands for a unit of a pedagogical process driven by the four kinds of awareness (C, S, G and F) brought about in a variation interaction. According to Leung, in a pedagogical situation, these four types of variation interaction act together in a concerted way to bring about discernment, as shown in Figure 1.

According to Leung (2012), the circular arrows and the dotted rectangle indicate that a mutually enhancing interaction between contrast and generalisation is at work to bring about awareness of dimensions of variation or critical features. Leung posits that the process of mathematical understanding is sequenced by a chain of such variation interactions in which simultaneity and focus of attention play critical roles (Figure 2).

Each of the discernment units in Figure 2 represents a developing mathematical concept that is fused together by a process of contrast and generalisation driven by separation, as shown in Figure 3.

This pedagogical model (Figure 3) shows how a lesson or series of lessons consists of a sequence of variation interactions that increases in sophisticated levels of contrast, reflecting the evolution of an idea from primitive stage to a more formal mathematical stage.
Fusion: Simultaneous awareness of critical features and/or dimensions of variation

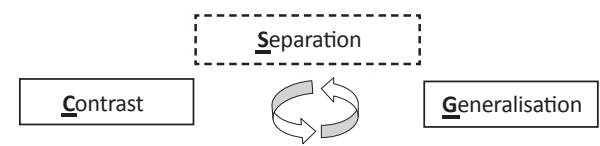

Source: Leung, A. (2012). Variation and mathematics pedagogy. In J. Dindyal, L.P. Cheng, \& S.F. Ng (Eds.), Proceedings of the 35th Annual Conference of the Mathematics Education Research Group of Australasia (pp. 433-440). Singapore: MERGA. Available from http:// www.merga.net.au/documents/Leung_2012_MERGA_35.pdf

FIGURE 1: A discernment unit driven by types of variation interaction.

Discernment Unit One $\Rightarrow$ Discernment Unit Two $\Rightarrow$ Discernment Unit Three

Source: Leung, A. (2012). Variation and mathematics pedagogy. In J. Dindyal, L.P. Cheng, \& S.F. Ng (Eds.), Proceedings of the 35th Annual Conference of the Mathematics Education Research Group of Australasia (pp. 433-440). Singapore: MERGA. Available from http:// www.merga.net.au/documents/Leung_2012_MERGA_35.pdf

FIGURE 2: A pedagogical time sequence on the understanding of a mathematical object of learning.

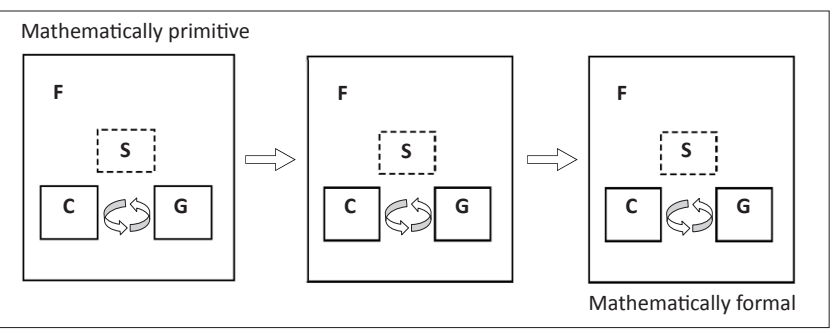

F, fusion; C, contrast; S, separation; G, generalisation.

Source: Leung, A. (2012). Variation and mathematics pedagogy. In J. Dindyal, L.P. Cheng, \& S.F. Ng (Eds.), Proceedings of the 35th Annual Conference of the Mathematics Education Research Group of Australasia (pp. 433-440). Singapore: MERGA. Available from http:// www.merga.net.au/documents/Leung_2012_MERGA_35.pdf

FIGURE 3: A model of mathematics pedagogy based on variation.

\section{Methodology}

The analysis focused on discernment units as described by Leung (2012). These units were selected from five lesson transcripts of a Grade 11 teacher who was teaching number sequences. The demarcation of a discernment unit combined ideas from Leung, who posits that it is like a function of what is being varied, and Andrews's (2009) idea of a lesson episode, which he defined as that part of a lesson where the teacher's didactic intent remained constant. The tables summarising each discernment unit were modified from Tong's (2012) study, which used similar summaries of lessons on reading. In Tong's study it was possible to use one table to summarise each of the different variation patterns. Because of the nature of mathematics, Leung's proposition was that in a pedagogical situation, the four types of variation interaction act together in a concerted way to bring about discernment. Consistent with this view, separation of each variation pattern would not have been productive in this article; hence, I modified the approach and combined summaries of the four variation patterns in one discernment unit. So within these discernment units, I looked at which aspects were fixed, what was varied and how it was varied, and what was thus available for discernment by the learners. Because discernment is about how learners responded to the teacher's variation activities, learner responses were critical as evidence of discernment in this analysis; hence, they are labelled as Learner 1 or Chorus 1 for easier reference in the discussion. 


\section{Data presentation and analysis Discernment unit 1}

At this stage of the lesson the teacher had just worked through the logic behind the general term for all linear number sequences, which shows that to get any term $\mathrm{a}_{n}$ we start from the starting point $\mathrm{a}_{1}$ then add or subtract the constant difference repeatedly $(n \pm 1)$ times. This had been summarised on the board as $a_{n}=a_{1}+(n \pm 1) d$. From this general rule an explicit rule for a specific linear sequence could then be deduced. The lesson then progressed thus:

Teacher: Suppose we are required to find the explicit rule for: [teacher writes three sequences on the board]

(a) $4 ; 7 ; 10 ; 13 ; \ldots$ (b) $2 ; 5 ; 8 ; 11 ; \ldots$ (c) $-10 ;-7 ;-4 ;-1 ; \ldots$

Chorus 1: We are still working sir.

Teacher: [After a pause] Ok, ok, anybody who got it, the explicit rule [three learners are called to work $a, b$, and $c$ on board].

Learner 1: (a) $\mathrm{T}_{n}=3 n+1$

Learner 2: (b) $\mathrm{T}_{n}=3 n-1$

Learner 3: (c) $\mathrm{T}_{n}=3 n-13$

Teacher: Alright, ok, ok, ok, ok. I want us to observe a pattern here. What have you observed as the constant difference in each of the sequences that I have given you?

Chorus 2: Its 3.

Teacher: Ok, between any two consecutive numbers there is a difference of 3 . What have you observed about the explicit rule in each of the three cases?

Learner 4: The three rules all start with $3 n$ then blablabla.

Teacher: $\quad \mathrm{Ok}$, so if you were given the sequences

(d) $3 ; 5 ; 7 ; 9 ; \ldots$ and (e) $-4 ;-2 ; 0 ; 2 ; \ldots$

and asked to find the explicit rule, what would you say?

Chorus 3: $\mathrm{T}_{n}=2 n$ then blablabla for both of them.

Teacher: Ooooh yes! Interesting, isn't it? Anybody with questions so far?

Comment: Let us recall that contrast is an awareness brought about by experiencing difference. In this discernment unit one can see an awareness that was brought about by a contrast (C) variation in that the teacher provided two different sets of sequences $\{a ; b ; c\}$ and $\{d ; e\}$ to enable learners to discern that a linear sequence with a common difference of 3 is not the same as that with a common difference of 2. Once this distinction was made by the learners, one can see a 'refined contrast' or separation $(S)$ as the teacher selectively draws learners' attention to the sameness of the set of sequences \{a; b; c\}. Through systematically varying the sequences and not varying the constant difference of 3 learners were enabled to separate the constant difference of 3 as a critical factor that identifies a linear sequence of the form $\mathrm{T}_{n}=3 n+c$. Similarly, within the sameness of the set of sequences $\{d$; $e\}$, the learners could also separate and discern the constant difference 2 as a critical factor that identifies a linear sequence of the form $\mathrm{T}_{n}=2 n+c$.
Let us recall that generalisation is a verification and conjecture-making activity enabling learners to check the general validity of a separated out pattern. In this case after observing the links between the common difference and $m x$ value of the explicit rule, learners were then enabled to generalise $(\mathrm{G})$ that $\mathrm{T}_{n}=3 n+$ blablabla for the first set of sequences $\{a ; b ; c\}$ and that $T_{n}=2 n+$ blablabla for the set $\{d$; e $\}$. In terms of fusion, which is brought about through covariation, it is important to recall that this kind of awareness (fusion) can result from either a synchronic simultaneity or a diachronic simultaneity. In this discernment unit we see more of the latter in that by varying the sequences with a common difference of 3 first and then later varying those with a common difference of 2 the teacher opened up opportunities for learners to integrate (hence fusion, F) through diachronic simultaneity. This enabled them to make the links between the common difference and the $m x$ value of the explicit rules for all linear sequences.

\section{Discernment unit 2}

At the end of discernment unit 1, the teacher asked if learners had any questions:

Learner 5: Can I please ask a question? The thing nee; you see I just want to find out why isn't that you guys to find the general term why can't you write $\mathrm{T}_{n}=$ blablabla +3 [constant difference] ? Why do you have -1 instead? That is my question.

Teacher: Ok, ok alright I see what you mean. Let's use the following examples and see what is happening. [Writes on the board]

(f) $4 ; 7 ; 10 ; 13 \ldots$ (g) $1 ; 4 ; 7 ; 10 ; 13 \ldots$ (h) $7 ; 10 ; 13 ; \ldots$

Teacher: I now want you to work out the explicit formula for these three sequences.

Learner 6: (f) $\mathrm{T}_{n}=3 n+1$

Learner 7: $\quad(\mathrm{g}) \mathrm{T}_{n}=3 n-2$

Learner 8: $\quad(\mathrm{h}) \mathrm{T}_{n}=3 n+4$

Teacher: Ok, let's observe something here. If you look carefully you will notice that I have been playing around with the same figures to generate three different sequences. What is it that I have not changed?

Chorus 4: The common difference is the same its 3 sir in all the three cases.

Teacher: Ok, and we have agreed that when this common difference is 3 then the explicit rule will be $\mathrm{T}_{n}=3 n+$ blablabla. So what is it that I have changed?

Learner 9: I think you have just changed the starting point for each of those sequences.

Teacher: $\quad$ Ok, and what do we observe in the second part of our explicit rules?

Chorus 5: The second part is different each time.

Teacher: This seems to suggest some link of some sort between this starting point and the plus blablabla of this explicit formula. Who would like to try

TABLE 1: Summary of discernment unit 1.

\begin{tabular}{llll}
\hline Varied & Not varied & Critical features to be discerned & Evidence of learner discernment \\
\hline Sequences a, b, c & Common difference of 3 & Link between common difference and the $m x$ value in the explicit rule & $\begin{array}{l}\text { Learner 4: The three rules all start with } 3 n \text { then } \\
\text { blablabla. }\end{array}$ \\
Sequences d, e & Common difference of 2 & & Chorus $3: \mathrm{T}_{n}=2 n$ then blablabla for both. \\
\hline
\end{tabular}


and explain this relationship to us? [Pointing to a learner]: Can you come to the board and use these two examples $(3 ; 7 ; 11 ; 15 \ldots$ and $3 ; 5 ; 7 ; 9 \ldots)$ to explain what you have seen.

Learner 10: [Explaining how to get the second part -1 of the explicit rule $T_{n}=4 n-1$ for the sequence $3 ; 7 ; 11 ; 15 \ldots$ In this sequence, 3 (first term) minus 4 (common difference) gives us -1 . Even here [pointing $T_{n}=2 n+1$ for the sequence $3 ; 5 ; 7 ; 9$...] the 3 (first term) minus 2 (common difference) gives us 1.It always works.

Chorus 6: Hoooo [and clapping their hands].

Teacher: $\quad$ Ok, someone has made an observation here to say alright, this 2 [pointing to the 2 in $T_{n}=2 n+1$ ] where is it coming from, it is the difference between any successive terms. Then to get this 1 he simply says $3\left[a_{1}\right]$ minus 2 [common difference] which gives us 1. Ok does it always work? Ok let's see if it works here. [Pointing to $1 ; 4 ; 7 ; 10$...] So according to him the explicit rule here should be $\mathrm{T}_{n}=3 n-2$ ?

Chorus 7: $\quad$ Agreed! Yes! Yes! True! [Learners go on to prove the rule by generating $1 ; 4 ; 7 ; 10 \ldots$ ]

Comment: In this discernment unit, one can see why Leung (2012) posited that variation interaction can be teacher designed or learner initiated and that it should not always be assumed that learners will always understand an object of learning in the same way as the teacher intended. For example, Learner 5 asked why the idea of constantly adding on the common difference was not coming out in the explicit rule. According to Ling (2012) this is mainly because the two possible ways of seeing the same thing had not been placed in the foreground and so variation was not effective in bringing out the contrast between the 'add on' of the common difference in the recursive and the $(+c)$ in the explicit rule. Literature confirms that learners usually see linear sequences through recursion (Blanton, 2008). This therefore suggested that this (+ blablabla) part of the explicit rule was a critical feature that the teacher needed to make the object of variation. The teacher through 'refined contrast' variation then steered the learners' awareness and hence opened up opportunities for learners to separate (S) the critical links and discern that the second part $(+c)$ of the explicit rule was equivalent to term one minus the common difference i.e. $\left(a_{1}-d\right)$. Because Learner 5 and perhaps others had now gained a new way of seeing this part of the explicit rule it can be argued that a contrast variation was experienced. According to Ling (2012, p. 86), contrast (C) can also be brought about when learners experience variation between their prior knowledge and the new way of seeing the same thing, as intended by the teacher.
When the teacher probed: 'Does it always work?', one can see how the teacher is using generalisation $(G)$ as a verification and conjecture-making activity in which learners check the general validity of their separated out pattern (Chik \& Marton, 2012). In this discernment unit one can see fusion (F) as the learners' attention is focused on several aspects of the explicit rule under both synchronic and diachronic simultaneity.

\section{Discernment unit 3}

After the discussion on the connections between the recursive rule and the explicit rule the teacher then posed another question:

Teacher: Let us go back to the three examples that we started off with. In each case I want us to determine the 10 th term using any of the rules that we have seen so far [three learners provide answers for sequences $a, b$, and $c$.

Learner 11: (a) 31

Learner 12: (b) 29

Learner 13: (c) 17

Teacher: Which of the two rules recursive or explicit did you use?

Chorus 8: Explicit sir, it's much easier and faster.

Teacher: Ok, let us explore this issue further. Is there any other way that we could have calculated or located the 10th or any other term in these sequences?

Learner 14: Sir, I think we could also use graphs to find the answers.

Chorus 9: Aaaaaah! How can you draw graphs here?

Teacher: Can somebody explain how?

Learner 15: Instead of writing $\mathrm{T}_{n}=3 n+1$ sir we could write $y=3 x+1$ where $y=\mathrm{T}_{n}$ and $x=n$ then we can make a table of values connecting the term numbers $(x)$ and their values $(y)$ then plot the values on the $x$ and $y$ plane [Cartesian].

Chorus 10: Hoooo [whilst clapping their hands. The class then makes the following table of values for the sequence: $y=3 x+1]:$

\begin{tabular}{|l|l|l|l|l|l|}
\hline$x$ & 1 & 2 & 3 & 4 & 5 \\
\hline$y$ & 4 & 7 & 10 & 13 & 16 \\
\hline
\end{tabular}

Teacher: I hope you are making sense of what is happening here. Because we have now run out of time, I want us to go home and try to make tables first then draw the graphs of the same tasks (a), (b) and (c) then we will discuss your findings tomorrow.

TABLE 2: Summary of discernment unit 2.

\begin{tabular}{|c|c|c|c|}
\hline Varied & Not varied & Critical features to be discerned & Evidence of learner discernment \\
\hline $\begin{array}{l}\text { The starting points of } \\
\text { sequences } f, g, h\end{array}$ & Common difference of 3 & $\begin{array}{l}\text { Link between starting point of a number } \\
\text { sequence and the second }(+c) \text { part of the } \\
\text { explicit rule }\end{array}$ & Chorus 5: The second part is different each time. \\
\hline
\end{tabular}

Chorus 6 \& Chorus 7: The class agrees and learners go on to prove the rule.

\begin{tabular}{|c|c|c|c|}
\hline Varied & Not varied & Critical features to be discerned & Evidence of learner discernment \\
\hline \multirow{2}{*}{$\begin{array}{l}\text { The process or } \\
\text { representations from } \\
\text { numerical, recursive and } \\
\text { explicit to table form }\end{array}$} & The sequences $a, b, c$ & $\begin{array}{l}\text { The different ways in which linear } \\
\text { sequences could be represented }\end{array}$ & $\begin{array}{l}\text { Learner } 15 \text { : Instead of writing } \mathrm{T}_{n}=3 n+1 \text { we could write } y=3 x+1 \text { [making } \\
\text { links between representations]. }\end{array}$ \\
\hline & & $\begin{array}{l}\text { The advantages and disadvantages of each } \\
\text { representation }\end{array}$ & Chorus 8: Explicit sir, it's much easier and faster. \\
\hline
\end{tabular}


Comment: Within this discernment unit one can see how the teacher has contrasted $(\mathrm{C})$ the different representations of linear sequences starting with the recursive rule, through the explicit rule, through tables for the corresponding values of $x$ and $y$. Let us recall that contrast can also be brought about when learners experience variation between their prior knowledge and the new way of seeing the same thing, as intended by the teacher. We notice this when the learners suddenly realised that $\mathrm{T}_{n}=3 n+1$ could be written as $y=3 x+1$, which they were familiar with.

In this discernment unit the teacher also makes deliberate attempts to systematically draw learners' attention to the critical features of each representation, thereby helping the learners to separate $(S)$ and hence discern certain advantages and disadvantages of working with each representation. For example, the recursive rule shows both the starting point and the constant difference of the linear sequence clearly, which the explicit rule does not. However, the explicit rule has an advantage in that it enables one to get straight to any term value without having to go via the previous term, which is the limitation of the recursive rule. This is evidenced in the learners' responses when they were asked to determine the tenth term of each of the sequences. Their responses (Chorus 8 ) showed that it was easier for them to use the explicit rule to get the tenth value. Probing the learners for another method that could be used to determine the tenth term enabled the learners to again discern the links between the explicit rule, $\mathrm{T}_{n}=3 n+1$, and $y=3 x+1$ (its equivalent form when written in terms of $x$ and $y$ ), which they were more familiar with. This was critical in that this formed the foundation for learners to generalise $(G)$ why such number sequences are called linear. The table then gives a visual connection between the term number (input) and its value (output) in a way that makes it easier for learners to identify how terms change from one to the next. This visual link between the input and the output might not have been discerned by the learners if the teacher had not contrasted the recursive and the explicit rules simultaneously (fusion, F).

\section{Discernment unit 4}

The following day learners brought their work on graphs. The teacher had drawn the graphs on an A0 size of paper and pinned it on the board for the classroom discussion (see Figure 4):

Teacher: Ok, let us proceed from where we left. What can you say about the graphs that you drew?

Chorus 11: They are all straight line graphs. They are parallel lines. They are increasing graphs.

Teacher: Ok, good observations. With many sequences it may be easy to notice how terms change from one to the next if the terms are listed numerically. However, listing the terms does not show other characteristics. For example, when a pattern in a number sequence is found by adding or subtracting the same number every time then the sequence is called an arithmetic or linear sequence because as you can see from the graphs all arithmetic sequences make straight line graphs - something which we could not have seen from listing the numbers. But why are the lines parallel?

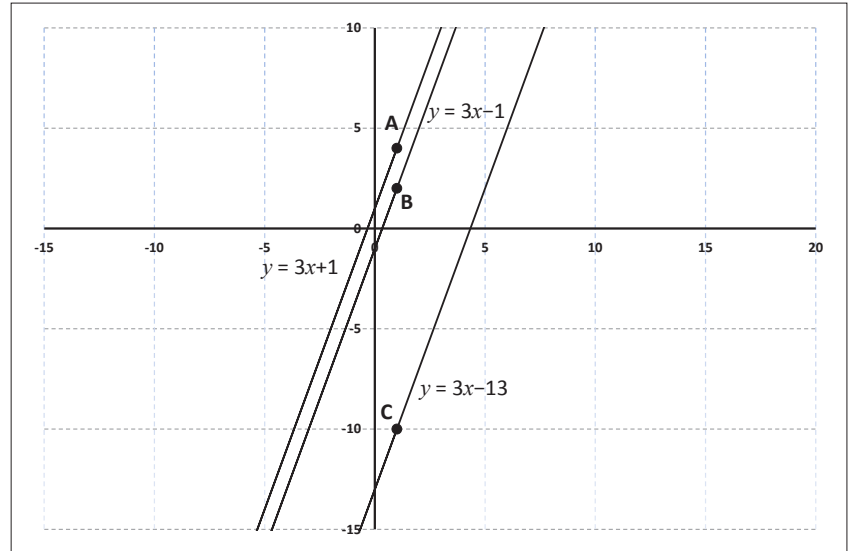

FIGURE 4: Graphs of the three arithmetic sequences.

Chorus 12: Sir, just by looking at them we can see that they are parallel.

Teacher: Yes I agree, but how else can we tell they are parallel?

Learner 16: These lines, sir, have the same gradient.

Teacher: Ok, somebody has made an observation that these lines have the same gradient. Ok, do you agree? If so how do you determine that gradient? [There is some discussion with some learners pointing to the $3 x$ or $3 n$ in the explicit rule, others were counting the blocks to determine the $\frac{d y}{d x}$, i.e. the change in y over the change in $x$. Eventually the class reaches a consensus]

Chorus 13: The gradient is the same as the common difference when the terms are listed numerically.

Teacher: Now let us come back to the question raised earlier that why do we have -1 in the explicit rule instead of the constant difference. In the recursive rule the common difference is added on to the previous term each time so it is visible every time we calculate a term value. In the explicit rule this common difference is considered as the rate of change, i.e. as we move from $t_{1}$ to $t_{2}$ and so on, the numbers increase by 3 . Hence if we wrote the arithmetic sequence in the standard function form $y=m x+b$, it is the $m$ value which is equal to 3 and not the $b$. So the $b$ is not standing for the common difference hence we cannot say $\mathrm{T}_{n}=$ blablabla +3 as you suggested (pointing to the learner who had asked earlier). Who can tell us what the $b$ is standing for in this case?

Learner 17: Sir, it is standing for the point where the graph cuts the $y$-axis.

Teacher: What other term do we use for that?

Learner 18: The $y$-intercept, sir.

Teacher: How is this linked with the starting point of each sequence? Remember in the recursive rule we have said we always start at $a_{1}$. Can you locate the three starting points for the three graphs that you have drawn?

Chorus 14: [The learners locate the points $A, B$ and $C$ as the starting points]

Teacher: Can you see that in each case to move from each starting point (A, B and $\mathrm{C}$ ) to the point where the graph cuts the $y$-axis we have to move 1 step back along the $x$-axis. It's like getting to a point we can call $a_{0}$. Let us remember that each time we move 
one step on the $x$-axis we actually go up or down three steps (common difference) along the $y$-axis. This is the reason why in the standard form $y=m x+b$; the $b$ value or $a_{0}$ can always be found by $a_{1}$ (starting point) minus $d$ (common difference). Simply put when given the starting point in a linear sequence move backwards by the common difference and you have the $b$-value of the explicit formula. That is exactly why (learner's name) method always worked.

Comment: From this discernment unit one can see contrast (C) in the learners' changed way of seeing different representations of a linear sequence. One can also see separation (S) in the manner in which learners were enabled to discern the links between critical features of a linear sequence when represented in a different way. From the teacher's discussion, one can observe that by representing all three sequences on one graph, a fusion $(F)$ is foregrounded and a number of mathematical connections are triggered. So in this discernment unit through the teacher's varying and not varying, learners were enabled to discern and generalise (G) that all the sequences they had worked with so far could be represented graphically by straight lines that are parallel (same gradient), that are all 'increasing' (gradient is positive in all the three cases), and whose slope $m$ is exactly the same as the common difference, $d$. It was also possible for learners to discern that the graphical representation, especially when all the sequences had been drawn on the same Cartesian plane, became more like a ready reckoner: it allowed quick interpolation of values. Knowing one of the two values ( $x$ or $y$ ) allowed learners to interpolate the other value by following across (or up) to one axis and then down (or across) the other axis to read the unknown data that lies within the known data range but was not measured initially or given in the initial listing of terms. For example, just by moving up the vertical line $(x=1)$, they were able to read off (Chorus 14) the starting points ( $y$ values at A, B and C) for each of the sequences that had been represented on this graph. By moving up the vertical line $x=10$, they were also able to read off the tenth values of the different sequences without much effort. In fact it can be argued that the way tasks were structured through variation opened up space for deep mathematical reasoning that would have enhanced learners' higher order thinking skills and understanding of number patterns. Consistent with Leung's model as shown in Figure 3, one can see how number patterns were presented from the primitive listing of terms to the more formal and precise way through the use of recursive, explicit and graphical representations. It can therefore be argued that these forms of variation (contrast, separation, generalisation and fusion) provided a hierarchical system of experiencing processes through forming concepts (Gu, Huang \& Marton, 2004). Watson and Mason (2006) concluded that such results created by learners become tools for more sophisticated mathematics, and are a significant component of their mathematical progress.

\section{Ethical considerations}

The Department of Education granted approval to proceed with this study under permit T-728 P01/02 U-848. At the institutional level, the university ethics committee granted approval under protocol 2007EC007. At the school level, the researcher received informed consent from teachers and parents of the learners who participated in the study.

\section{Summary}

This article was triggered by the paradoxical observation that a Grade 11 teacher taught number sequences in a manner that would have been described generally as teacher led, content focused and transmission based, yet the instructional activities seemed to create opportunities for learners to make deep mathematical connections. Despite the fact that this approach might have been described pejoratively as inhibitive to learners' deep understanding, the researcher hypothesised that something could be learnt from this teacher's instructional practices. Borrowing Leung's (2012) framework of a discernment unit based on the theory of variation, the analysis was aimed at examining the extent to which learners were provided with opportunities to develop mathematical concepts. Although the results are exemplified through four discernment units, all the five lessons on number patterns that were observed for this teacher showed that indeed all the characteristics of a strategic use of variation were at the centre of the teacher's instructional activities. The discussion and illustrations thereof highlight how opportunities were created for learners to discern a number of important mathematical ideas. Starting from a primitive interpretation of a linear sequence through recursion, that is, $a_{n}=a_{1}+(n \pm 1) d$, one can notice how the learners moved to more sophisticated stages through establishing the links between the common difference and the coefficient of $n$ in the explicit rule, the links between the first term and common difference to determine the $b$ value of the explicit rule, and then eventually justifying and linking these relationships with gradients and $y$-intercepts on graphs of the same sequences. This way it can be argued that learners were forming a hierarchy of gradually refined concepts of number patterns through the teacher's approach of varying and not varying certain things.

TABLE 4: Summary of discernment unit 4.

\begin{tabular}{|c|c|c|c|}
\hline Varied & Not varied & Critical features to be discerned & Evidence of learner discernment \\
\hline \multirow{3}{*}{$\begin{array}{l}\text { From a numerical representation to a graphical } \\
\text { representation of a linear number sequence }\end{array}$} & The sequences $a, b, c$ & Why such sequences are referred to as linear & Chorus 11: They are all straight lines, sir. \\
\hline & & Links between constant difference and the gradient & $\begin{array}{l}\text { Chorus 13: Gradient is the same as the } \\
\text { common difference. } \\
\text { Chorus 11: They are parallel. }\end{array}$ \\
\hline & & Links between the $\left(a_{1}-d\right)$ and the $y$-intercept & Learner 17 \& Learner 18: The $y$-intercept, sir. \\
\hline
\end{tabular}


It can be concluded that the ways in which strategies of variation are orchestrated in a class can foster meaningful learning. The four discernment units as outlined fully illustrate this point. These lessons were generally teacher led; there was nothing 'novel' about the tasks, they were just standard textbook tasks, but the manner in which the teacher varied the activities and kept some constant indeed created opportunities for learners to discern a number of important mathematical ideas.

\section{Implications for theory and classroom practice}

In terms of contributing to theory, the warning inherent in many theoretical analyses is that if we focus on the insights on teaching and learning rather than arguing about the differences between the theories at the philosophical level, then we will indeed find that many of the teaching approaches, strategies and designs suggested are similar and compatible (Ling, 2012). Through the activities within the four discernment units one can see how a pedagogy based on variation provides such a harmonising framework in which a predominantly teacher-led teaching approach supports deep understanding of mathematical concepts.

In terms of contributing to curriculum development, this article contributes to harmonising the simplistic and bogus dichotomies that have been set up in the curriculum, which need to be addressed in future policy documents. The South African curriculum statements create uncalled-for polarity between the 'old' and the 'new' curriculum, but what is not acknowledged is that the 'new' is not often seen, even in well-resourced countries where school reform movements have been promoting these ideas for many years.

With regard to teacher education, both literature and empirical evidence suggest that teacher educators have a legal, professional, moral and civic obligation to provide their student teachers with models of teaching that work in their contexts. From that perspective, it can be argued that this article could be of benefit to teacher education in that it explores a model of teaching mathematics that has been tried and tested elsewhere and locally and which might be considered for further trials with student teachers.

In terms of classroom practice, Vithal and Volmink (2005) posit that waves of curriculum change often result in the implementation of an eclectic mixture of approaches. The 'new' curriculum demands a radical shift from the traditional teacher-led approaches that teachers are familiar with, yet it does not provide a model of what it might mean to teach for conceptual understanding. Teaching with variation could provide teachers with this much-needed bridge between the 'old' that they are familiar with and the 'new' that is espoused. This is important for educators as they struggle to make sense of the seemingly contradictory requirements of the 'new' curriculum.

With reference to how learners could benefit from such studies, empirical evidence shows that lack of insight into the pedagogical theories underpinning the reform movement may cause confusion even amongst experienced teachers, which leads to learners having neither conceptual nor procedural knowledge (Schollar, 2004). The implication for schools and educators seems clear: mathematics education programmes in schools should incorporate both teacher-led and learner-centred approaches in their instruction practices.

\section{Acknowledgements}

I acknowledge the Department for International Development for funding the $\mathrm{PhD}$ study from which this article is drawn.

\section{Competing interests}

I declare that I have no financial or personal relationships that may have inappropriately influenced me in writing this article.

\section{References}

Adler, J. (2009). A methodology for studying mathematics for teaching. Recherches en Didactique des Mathematiques, 29(1), 33-58.

Andrews, P. (2009). Comparative studies of mathematics teachers' observable learning objectives: Validating low inference codes. Educational Studies in Mathematics, 71(2), 97-122. http://dx.doi.org/10.1007/s10649-008-9165-x

Blanton, M. (2008). Algebra and the elementary classroom: Transforming thinking, transforming practice. Portsmouth, $\mathrm{NH}$ : Heinemann.

Brodie, K., \& Pournara, C. (2005). Towards a framework for developing and researching group work in mathematics classrooms. In R. Vithal, J. Adler, \& C. Keitel (Eds.), Researching mathematics education in South Africa: Perspectives, practices and possibilities (pp. 28-72). Cape Town: HSRC Press.

Chik, P.P.M., \& Marton, F. (2010). Chinese pedagogy and pedagogy for learning Chinese. In F. Marton, S.K. Tse, \& W.M. Cheung (Eds.), On the learning of Chinese (pp. 9-29). Singapore: Sense Publishers. Available from https://www. sensepublishers.com/media/721-on-the-learning-of-chinese.pdf

Gu, L., Huang, R., \& Marton, F. (2004). Teaching with variation: A Chinese way of promoting effective mathematics learning. In L. Fan, N.Y. Wong, J. Cai,
$\& \mathrm{~S}$. Li (Eds.), How Chinese learn mathematics: Perspectives from insiders $\&$ S. Li (Eds.), How Chinese learn mathematics: Perspectives from insiders
(pp. 309-347). Singapore: World Scientific Publishing. http://dx.doi. org/10.1142/9789812562241_0012

Leung, A. (2010). Empowering learning with rich mathematical experience: Reflections on a primary lesson on area and perimeter. International Journal for Mathematics
Teaching and Learning. Available from http://www.cimt.plymouth.ac.uk/journal/ Teaching and

Leung, A. (2012). Variation and mathematics pedagogy. In J. Dindyal, L.P. Cheng, \& S.F. $\mathrm{Ng}$ (Eds.), Proceedings of the 35th Annual Conference of the Mathematics Education $\mathrm{Ng}$ (Eds.), Proceedings of the 35th Annual Conference of the Mathematics Education
Research Group of Australasia (pp. 433-440). Singapore: MERGA. Available from http://www.merga.net.au/documents/Leung_2012_MERGA_35.pdf

Ling, M.L. (2012). Variation theory and the improvement of teaching and learning. Gothenburg, Sweden: Acta Universitatis Gothoburgensis. Available from http:// gupea.ub.gu.se/handle/2077/29645

Long, C. (2005). Maths concepts in teaching: Procedural and conceptual knowledge. Pythagoras, 62, 59-65. http://dx.doi.org/10.4102/pythagoras.v0i62.115

Marton, F. (2009, December). Sameness and difference in learning. Paper presented at the Swedish Research Links Symposium on Phenomenography and Variation Theory, University of Hong Kong, Hong Kong.

Marton, F., \& Booth, S. (1997). Learning and awareness. Mahwah, NJ: Lawrence Erlbaum Associates.

Marton, F., \& Tsui, A.B.M. (2004). Classroom discourse and the space of learning. Mahwah, NJ: Lawrence Erlbaum Associates.

Mayer, R.E. (2009). Constructivism as a theory of learning versus constructivism as a prescription for instruction. In S. Tobias, \& T.M. Duffy (Eds.), Constructivist instruction. Success or failure? (pp. 184-200). London: Routledge, Taylor \& Francis Group.

Mhlolo, M.K., Venkat, H., \& Schäfer, M. (2012). The nature and quality of the mathematical connections teachers make. Pythagoras, 33(1), Art. \#22, 9 pages. http://dx.doi.org/10.4102/pythagoras.v33i1.22

Schollar, E. (2004). Primary mathematics research project. Johannesburg: Eric Schollar \& Associates.

Tong, S.Y.A. (2012). Applying the theory of variation in teaching reading. Australian Journal of Teacher Education, 37(10), 1-19. http://dx.doi.org/10.14221/ ajte.2012v37n10.3

Vithal, R., \& Volmink, J. (2005). Mathematics curriculum research: Roots, reforms, reconciliation and relevance. In R. Vithal, J. Adler, \& C. Keitel (Eds.), Researching mathematics education in South Africa: Perspectives, practices and possibilities mathematics education in South Afric
(pp. 3-27). Cape Town: HSRC Press.

Watson, A., \& Mason, J. (2006). Seeing an exercise as a single mathematical object: Using variation to structure sense-making. Mathematical Thinking and Learning 8, 91-111. http://dx.doi.org/10.1207/s15327833mt|0802_1 